\title{
Evaluation of carotid intima media thickness in early onset androgenetic alopesia
}

\section{Erken başlangıçlı androgenetik alopeside karotis intima kalınlığının değerlendirilmesi}

\author{
Emine ALTUNTAŞ ${ }^{1}$, Hülya NAZiK ${ }^{2}$, Feride ÇOBANGÜL ${ }^{3}$, Nurcan ARAT ${ }^{4}$
}

\begin{abstract}
Purpose of this study was to evaluate of carotid intima- media thickness (CIMT) together with biochemical parameters in male patients with early-onset androgenetic alopecia (AGA) without risk factors for cardiovascular disease and to reveal the relationship between early-onset AGA and cardiac arrhythmia, atherosclerosis, metabolic syndrome in patients with $P$ wave and $Q T$ dispersion in electrocardiography. Forty men with early onset AGA and 50 healthy men without AGA in the age group of 18-35 years were included in this study. We compared the biochemical values, blood pressure, carotid intima- media thickness (CIMT), echocardiographic(echo) and electrocardiographic (ECG) parameters. The mean age was $28.03 \pm 4.95 /$ years and the mean CIMT was $0.63 \pm 0.12 \mathrm{~cm}$ in the group with early onset $A G A$. The mean age was $28.95 \pm 5.03$ /years and the mean CIMT was $0.51 \pm 0.1 \mathrm{~cm}$ in the control group. CIMT was correlated with AGA $(p<0.05)$. The mean HOMA-IR (Homeostatic Model Assessment-Insulin Resistance) index was $2.35 \pm 1.97$ in the patient group and $1.85 \pm 1.65$ in the healthy group. HOMA-IR is related with early onset AGA $(p<0.05)$. On the other hand, echo and ECG parameters were not correlated with early onset AGA. The relationship between CIMT, HOMA-IR and early onset AGA may indicate that premature atherosclerosis is present in these patients. However, since clinical conditions of atherosclerosis may appear in the early onset AGA, appropriate screening methods should be used.
\end{abstract}

Keywords: Androgenetic alopesia, carotid intima media thickness, insulin resistance
Öz

Bu çalışmanın amacı, kardiyovasküler hastalık açısından risk faktörü olmayan erken başlangıçlı androgenetik alopesili (AGA) erkek hastalarda karotis intima media kalınlığının (KiMK) biyokimyasal parametrelerle birlikte değerlendirilmesi ve hastalarda elektrokardiyografide $P$ dalga ve QT dispersiyonu bakılarak erken başlangıçlı AGA ile kardiyak aritmi, ateroskleroz, metabolik sendrom arasındaki ilişkinin ortaya konulmasıydı. Bu çalışma dermatoloji polikliniğine saç dökülmesi yakınması ile başvuran 18-35 yaş arası 40 hasta ile sağlıklı 50 kontrolden oluşmaktadır. Tüm bireyler çalışma konusunda bilgilendirildi ve aydınlatılmış onamı alındı. Çalışmadan dışlanma kriterleri akut koroner sendrom ile başvurmak, diyabetes mellitus, hipertansiyon, malignite öyküsü, hepatik ve renal yetersizlik öyküsünün bulunmasıydı. Tüm katılımcılara ekokardiyografi, karotis doppler ultrasonografi yapıldı, elektrokardiyografi çekildi, dinlenme halinde tansiyon ölçüldü ve hemogram, açlık kan şekeri, insülin düzeyi, lipit profili parametreleri bakıldı. Başvuruda bulunan AGA'lı grubun karotis intima media kalınlığı (KIMK) ortalaması 0,63 $\pm 0,12 \mathrm{~cm}$ kontrol grubunun ise $0,51 \pm 0,1 \mathrm{~cm}$ olup istatistiksel olarak anlamlıydı $(p=0,01)$. AGA'lı hastaların yaş ortalaması $28,03 \pm 4,95 /$ yıl olup, kontrol gru-

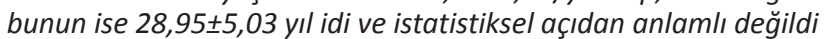
$(p>0,05)$. Elektrokardiyografide bakılan QT ile $P$ dalga dispersiyonları açısından yapılan değerlendirmede istatistiksel açıdan anlamlı fark oluşmadı ( $p>0,05)$. Insülin direnci için bakılan Homeostatic Model Assessment- insulinResistance (HOMA-IR) AGA'lı

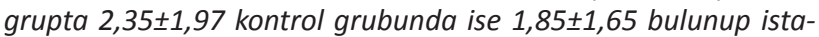
tistiksel açıdan anlamlıydı $(p=0,036)$. KIMK, HOMA-IR ile erken başlangıçlı AGA arasında ilişki saptanması bu hastalarda prematür ateroskleroz başlaması anlamına gelebilir. Bununla beraber, aterosklerozun klinik tabloları erken başlangıçlı AGA'lı hastalarda genç yaşlarda ortaya çıkabileceğinden uygun tarama yöntemleri kullanılmalıdır.

Anahtar kelimeler: Androgenetik alopesi, karotis intima media kaıınlığı, insülin direnci

Received: 02.01.2017

Accepted: 21.02.2017

${ }^{1}$ Zonguldak Atatürk State Hospital, Department of Cardiology, Zonguldak, Turkey

${ }^{2}$ Bingöl State Hospital, Department of Dermatology, Bingöl, Turkey

${ }^{3}$ Elazığ Educational Research Hospital, Department of Dermatology, Elazığ, Turkey

${ }^{4}$ Istanbul Bilim Universty, Department of Cardiology, İstanbul, Turkey

Yazışma adresi: Emine Altuntaş, Zonguldak Atatürk State Hospital, Department of Cardiology, Zonguldak, Turkey

e-mail: emine_altuntas@hotmail.com 


\section{GiRiş}

Saçlı derideki kıl foliküllerinin minyatürleşmesi ile meydana gelen androgenetik alopesi (AGA) otozomal dominant kalıtılan ve sistemik hastalıklarla birlikte görülebilen nonskatrisyel saç dökülmesidir. Hormonlar, genetik yatkınlık varlığında foliküler yapıyı olumsuz etkiler. Saç siklusunda gözlenen değişikliklerin sonucunda terminal kıllar kısa ve ince vellus kılları haline gelir. Tanısı öykü ve fizik muayeneye dayanan AGA'nın 36 yaş öncesinde başlaması ve HamiltonNorwood sınıflandırmasına göre en az evre 3 olması erken başlangıçlı AGA olarak isimlendirilir ${ }^{1-4}$.

Başta testesteron olmak üzere dihidrotestesteron ve dihidroepiandesteron sulfat saç dökülmesine neden olan androjenik hormonlardır. Androgenetik alopeside gözlenen saç kaybı, frontal ve vertex bölgesindeki terminal kılların diffüz incelmesi şeklinde başlar ${ }^{1-3}$. Androgenetik alopesili erkek erişkin hastalarda saçlı derideki güçlü, kalın, pigmente terminal kılların ince, soluk, cansız vellus benzeri kıllarla aşamalı replasmanı farklı patternlerde olabilir. 1951 yılında Hamilton ve ark. ${ }^{6}$ kadın ve erkek bireylerde 1-8 arasında derecelenen ilk sınıflamayı ortaya koymuştur. Hamilton'un bu ilk sınıflamasında tip 1 prepubertal saçlı deriyi tanımlarken, tip 7 ve 8 ise yalnızca oksipital ve pariyetal bölgede kalan saçları gösterir. Yapılan bazı çalışmalarda erkeklerde androgenetik alopesi varlığı artmış kardiyovasküler hastalık ve myokard enfarktüsü riski ile ilişkilendirilmiştir ${ }^{7-9}$.

Otuz beş yaş öncesi ortaya çıkan erken başlangıçlı AGA tanısı olan hastalarda, hiperinsülinemi ve insulin direnciyle ilişkili olabilecek obezite, hipertansiyon, dislipidemi insidansının arttığı bildirilmiştir. İnsülinin kendisine ya da direncine bağlı oluşan vazokonstrüksiyon, azalmış kan akımı ya da foliküler mikroçevredeki besinsel yetmezliğin AGA'ya yolaçabileceği düşünülmüştür ${ }^{10}$.

Ateroskleroz ile ilişkili hastalıklar dünyada en önemli morbidite ve mortalite nedenidir. Ateroskleroz büyük ve orta boy muskuler arterleri tutarak sistemik bir hastalığın ortaya çıkmasına neden olur. Aterosk- lerotik hastalığın klinik bulguları ortaya çıktığında hastalık genellikle ileri safhadadır. Ardından yapılan girişimler genellikle palyatif veya ikincil korumaya yönelik olmaktadır ${ }^{11}$. Aterosklerotik değişikliklerin erken dönemde gösterilebilmesi, risk faktörlerinin azaltılmasında önemli bir paya sahip olabilir. Erken ateroskleroz döneminde arter duvarında intima media kalınlığında artış olmaktadır ${ }^{12}$. Ultrasonografi ile karotis intima-media kalınlığının (KіMK) asemptomatik kişilerin saptanmasında kullanılmaya başlanmış$\operatorname{tır}^{13}$. Karotis arterler derin yerleşimli olmadığından görüntülenmesi kolaydır ${ }^{14}$. Ultrasonografik yöntemlerle intima media kalınlığı ölçümü noninvaziv, kolay, maliyeti düşük ve tekrarlanabilirdir.

Bu çalışmanın amacı, kardiyovasküler hastalık açısından risk faktörü olmayan erken başlangıçlı AGA'lı erkek hastalarda KiMK'nın biyokimyasal parametrelerle birlikte değerlendirilmesi ve hastalarda elektrokardiyografide P dalga ve QT dispersiyonu bakılarak erken başlangıçı AGA ile kardiyak aritmi, ateroskleroz, metabolik sendrom arasındaki ilişkinin ortaya konulmasıydı.

\section{GEREÇ ve YÖNTEM}

Çalışmaya erken başlangıçlı AGA'ı 18-35 yaş arasındaki 40 erkek olgu ile benzer yaşlarda $A G A^{\prime}$ lı olmayan (Hamilton Norwood sınıflamasına göre sınıf 1) 50 erkek olgu alındı. Katılımcılara çalışma hakkında bilgi verilip bilgilendirilmiş onam formu dolduruldu ve yerel etik komiteden onay alındı. Sağlıklı grup dermatoloji polikliniğine kronik herhangi bir hastalık nedeni ile başvurmayan, erken başlangıçı androgenetik alopesi tanısı olmayan erkeklerden seçildi. Katılımcıların kellik düzeyi Hamilton Norwood skalası kullanılarak evrelendi. Evre 3 ve üzerinde olanlar çalışma grubuna dahil edildi. Diyabet, hipertansiyon, hiperlipidemi, renal ve karaciğer yetmezliği, koroner arter hastalığı olanlar, ailede koroner arter hastalığı öyküsü olanlar, obezler ve sigara kullananlar çalışmaya dahil edilmedi. Olgulardan 12 saat açlık sonrası kan örnekleri alınıp biyokimya laboratuvarında otoanalizörlerde (MINDRAY BS 2000, BeckmanCoulter DXI 800) açlık kan şekeri, lipit profili ve insülin düzeyi bakıldı. Bu 
sonuçlar doğrultusunda insülin direncini gösteren bir parametre olan Homeostatic Model AssessmentInsulin Resistance (HOMA-IR) değeri hesaplandı (HOMA-IR=Açlık Glukoz (mg/dL) X Açlık İnsülin (ulU/ $\mathrm{mL}) / 405)$.

Tüm hastaların tansiyon ölçümü poliklinik koşullarında 5-10 dk. dinlenme sonrası sol koldan sfingomanometre ile ölçülerek kaydedildi.

Vivid-5 ekokardiyografi cihazı (GE Medical Systems, Hortan, Norway) ile 2,5 MHz transdüser ile sol ve sağ kalp boşluklarının çapları, kapak yetersizlikleri derecesi, ejeksiyon fraksiyonu, sistolik pulmoner arter basıncı sol parasternal ve apikal pencerelerden bakılarak kayıt altına alındı.

Tüm hastaların PETAŞ KARDIOPET 600 ile 25 mm/sn hız ve $10 \mathrm{~mm} / \mathrm{mV}$ ile 12 derivasyonlu yüzey elektrokardiyografisi çekildi. Hastaların kalp hızı, P dalgası ve QT mesafeleri ölçüldü. QTd tüm derivasyonlardaki en küçük ile en büyük QT mesafesi ve $P$ dalgası arasındaki fark alınarak hesaplandı. QT mesafelerinden kalp hızına göre QTc değerleri Bazett formülü (QTc= QT/VRR msn) ile hesaplandı.

Karotis doppler ultrasonografi, supin pozisyonda ya- tan hastanın başı hiperekstensiyona getirilerek başa değerlendirilen tarafın tersine 30-40 derece açı verilerek yapıldı. Tüm incelemeler renkli doppler ultrasonografi cihazında (ToshibaAplio 500) $11 \mathrm{MHz}$ lineer prob kullanılarak gerçekleştirildi. Her iki KiMK, Iongitudinal eksende, bulbus bir santimetre proksimali arka duvarından plak olmayan bölgede, intimaya ait lümenle aradaki hiperekojen yansıma ile media tabakasının derinindeki media-adventisya tarafından oluşturulan hiperekojen yansıma arasından yapıldı ve ortalaması alındı.

\section{ISTATISTIKSEL ANALIZ}

Tüm istatistiksel analizler SPSS ver. 20 software (SPSS Inc., Chicago, IL, USA) ile yapıldı. HOMA-IR, trigliserid, total kolestrol, QT, sistolik kan basıncı dispersiyonu değişkenleri Kolmogrov-Smirnov testine göre normal dağılmadığı için Mann Whitney U ile; kalan değişkenler ise İndependent $T$ testi ile değerlendirildi. $p<0,05$ olduğunda gruplar arasında istatistiksel açıdan farklılık olduğu düşünüldü.

\section{BULGULAR}

Bu çalışma dermatoloji polikliniğine saç dökülmesi yakınması ile başvuran $18-35$ yaş arası 40 hasta ile sağ-

Tablo 1. Çalışmanın laboratuar verileri.

\begin{tabular}{llll}
\hline & Erken Başlangıçlı AGA'lı Grup & Sağlıklı Grup & p* \\
\hline Karotisintima-media kalınlığı (cm) & $0,63 \pm 0,12$ & $0,51 \pm 0,1$ & 0,01 \\
Sistolik kan basıncı (mmHg) & $104,51 \pm 3,1$ & $100,47 \pm 3,01$ & 0,984 \\
Diastolik kan basıncı (mmHg) & $69,51 \pm 3,10$ & $69,85 \pm 3,24$ & 0,709 \\
LVEF (\%) & $56,62 \pm 1,26$ & $56,98 \pm 1,48$ & 0,469 \\
LA çapı (cm) & $3,197 \pm 0,41$ & $3,19 \pm 0,48$ & 0,95 \\
P dalga dispersiyonu (msn) & $0,05 \pm 0,014$ & $0,0448 \pm 0,008$ & 0,14 \\
QT dispersiyonu (msn) & $0,0122 \pm 0,011$ & $0,0133 \pm 0,016$ & 0,864 \\
Total kolestrol & $189,03 \pm 45,52$ & $151,61 \pm 26,97$ & 0,001 \\
LDL (mg/dl) & $115,20 \pm 30,86$ & $95,85 \pm 26,40$ & 0,025 \\
HDL (mg/dl) & $47,86 \pm 8,36$ & $45,57 \pm 6,65$ & 0,304 \\
Trigliserid (mg/dl) & $156,34 \pm 77,91$ & $106,42 \pm 40,18$ & 0,023 \\
Açlık Kan Şekeri (mg/dl) & $94,48 \pm 7,13$ & $91,38 \pm 9,48$ & 0,193 \\
Insülin & $5,15 \pm 1,61$ & $4,67 \pm 2,28$ & 0,395 \\
HOMA-IR & $2,35 \pm 1,97$ & $1,85 \pm 1,65$ & 0,036 \\
& & & \\
\hline
\end{tabular}

LDL: Lowdensitylipoprotein, HDL: High densitylipoprotein, AGA: Androgenetikalopesi, HOMA-IR: Homeostatic Model Assessment-insulin Resistance, LVEF: Sol ventrikülejeksiyon fraksiyonu, LA: Sol atriyum, Total kolestrol, trigliserid ve HOMA-IR için $p$ değeri Mann Whitney U testi ile kalan değerler için Independent Student T testi ile hesaplandı.

msn: Milisaniye, mg: Miligram, dl: Desilitre, $\mathrm{cm}$ : Santimetre 
lıklı 50 kontrolden oluşmaktadır. Hastalar demografik açıdan benzerdi. Hasta grubunun sınıflara göre dağılımına bakıldığında evre 3'te 9 hasta (\%22,5), evre 4 'te 11 hasta $(\% 27,5)$, evre 5 'te 9 hasta $(\% 22,5)$, evre 6 'da 6 hasta (\%15), evre 7'de 5 hasta $(\% 12,5)$ vardı. Gruplar arasında yaş, HDL, insülin, açlık kan şekeri, sistolik ve diastolik kan basıncı açısından anlamlı farklılık oluşmadı (sırayla p değerleri; 0,52-0,304-0,3950,193-0,984-0,709). Ekokardiyografi ve elektrokardiyorafi açısından değerlendirildiğinde sol ventrikül ejeksiyon fraksiyonu, P ve QT dispersiyonu açısından benzerdi (sırasıyla $p$ değeri, 0,469-0,14-0,864).

Çalışma ile ilgili istatistiksel veriler Tablo 1 ve $2 a-2 b$ 'de özetlenmiştir. Bu verilere göre, total kolestrol, LDL, trigliserid, HOMA-IR düzeyleri ve KIMK AGA'lı grupta daha yüksek ölçülmüş olup gruplar arasında anlamlı fark oluşturdu (sırasıyla $p$ değeri, 0,001-0,025-0,0230,036-0,01).

Tablo 2a. Katilımcılara ait demografik veriler.

\begin{tabular}{|c|c|c|c|}
\hline & \multicolumn{2}{|c|}{$\begin{array}{l}\text { Erken Başlangıçlı } \\
\text { AGA'lı Grup }\end{array}$} & Sağlıklı Grup \\
\hline Hasta Sayısı & \multicolumn{2}{|c|}{$\mathrm{E}: 40 \mathrm{~K}: 0$} & $\mathrm{E}: 50 \mathrm{~K}: 0$ \\
\hline Ortalama Hastalık Süresi & \multicolumn{2}{|c|}{$3,79 \pm 2,70$} & - \\
\hline Hamilton Norwood & 3: 9 & 4: 11 & - \\
\hline Evresine Göre Hasta & 5: 9 & $6: 6$ & \\
\hline Sayısı & $7: 5$ & & \\
\hline
\end{tabular}

AGA: Androgenetik Alopesi

Tablo 2 b. Katilımclara ait demografik veriler.

\begin{tabular}{lll}
\hline & $\begin{array}{l}\text { Erken Başlangıçlı } \\
\text { AGA'lı Grup } \\
\text { n:40 }\end{array}$ & $\begin{array}{l}\text { Sağlıklı Grup } \\
\text { n:50 }\end{array}$ \\
\hline Yaş (yıl) & $\begin{array}{l}28,03 \pm 4,95 \\
\text { Ortalama Hastalık Süresi (yıl) }\end{array}$ & $\begin{array}{l}28,95 \pm 5,03 \\
-\end{array}$ \\
\hline
\end{tabular}

\section{TARTIŞMA}

Saçlı derinin frontal ve verteks bölgesindeki kılların diffüz incelmesi olarak başlayan AGA ile koroner arter hastalığı arasında bir ilişki olduğuna dair kanıtlar gün geçtikçe artmaktadır ${ }^{15}$. Patofizyolojideki en önemli rol serumdaki dehidrotestesteron/testesteron oranı yüksekliğine aittir ${ }^{16-19}$. Erken başlangıçlı AGA'lı has- talarda kardiyovasküler olay sıklığının daha yüksek olduğu tespit edilmiştir ${ }^{18}$. Androgenler, vasküler düz kas hücrelerinin direkt olarak proliferasyonunu stimüle ederek ya da ateroskleroz ile ilişkili risk faktörlerini modüle ederek (hiperlipidemi, hipertansiyon, insülin direnci) kardiyovasküler hastalıkların AGA'lı hastalarda erken ortaya çıkmasına neden olabilir ${ }^{20,21}$. Bu tip hastaların tespiti için kullanılabilecek yöntemlerden biri de KiMK ölçümüdür. Bu çalışmada erken başlangıçlı AGA'lı hasta grubunun KiMK'nın daha kalın olduğu saptandı $(p<0,01)$. Doğramacı ve ark. ${ }^{22}$ tarafından AGA'lı hastalarda yapılan çalışmada, vertekste saç kaybı olanlarda KiMK'nın arttığı saptanmıştır. Androgenetik alopesisi olan kadın ve erkek hastalarda KiMK'ın araştırıldığı bir başka çalışmada ise, her iki cinsiyet grubunda KiMK'nın arttığı görülmüştür ${ }^{23}$. Ertaş ve ark.'nın ${ }^{24}$ erken başlangıçlı AGA'lı hastalarda geleneksel ve geleneksel olmayan kardiyovasküler risk faktörlerini araştırmayı amaçladığı çalışmada KIMK'ın erken başlangıçlı AGA'lı hasta grubunda sağIıklı gruba göre istatistiksel olarak anlamlı derecede arttığı ortaya konulmuştur $(p<0,05)$.

Vasküler endotel disfonksiyonu kardiyovasküler sistemi ilgilendiren birçok hastalığa neden olabilir. Oksidatif stres endotel disfonksiyonu ve inflamasyonunu tetikleyerek ateroklerozu başlatmaktadır ${ }^{25}$. Vücuttaki oksidatif stres molekül miktarı ne kadar yüksek ise KiMK o oranda $\operatorname{artar}^{26}$. Kaya ve ark.'nın ${ }^{27}$ yaptığı bir çalışmada, erken başlangıçlı AGA ile oksidatif stres arasında ilişki saptanmıştır. Bu grup hastaların kan total oksidan seviyesi, total antioksidan seviyesi ve oksidatif stres indeksi yüksek saptanmıştır. Bu bilgiler ışığında erken $A G A^{\prime}$ lı grupta oksidatif stres ürünlerinin artışına bağlı olarak ateroskleroz sürecinin erken başlayabileceği düşünülerek KiMK yüksek ölçülebilir. Yaptığımız çalışmada, bunu destekleyici şekilde erken başlangıçlı AGA'lı grupta KiMK'de artış saptandı.

Ülkemizde yapılan bir çalışmada, ekokardiyografi ve elektrokardiyografi açısından AGA'lı ve normal grup arasında fark görmemiş olup, KiMK'nın AGA'lı grupta arttığı saptanmış $(p<0.05)^{22}$. Bu bulgular çalışmamızı desteklemektedir. 
Erken başlangıçlı AGA tanısı olan hastalarda insülin direnciyle ilişkili olabilecek obezite, hipertansiyon, dislipidemi insidansının artmasıyla insülin direncine bağlı oluşan vazokonstrüksiyon sonucu azalmış kan akımı foliküler mikroçevredeki besinsel yetmezliğin AGA'ya yol açabileceği düşündürmüştür ${ }^{10}$. AGA ile metabolik sendrom ilişkisi bazı çalışmalarda araştırılmış ve metabolik sendrom için bir erken belirteç olabileceği saptanmış ${ }^{28-30}$. Ekmekçi ve ark.'nın ${ }^{31} A G A^{\prime} l ı$ kadınlarda yaptığı çalışmada, açlık glukoz, C-peptit, insülin ve HOMA-IR düzeylerini sağlıklı gruba göre yüksek saptamıştır. Erken başlangıçlı erkek AGA'lı hastalarda da HOMA-IR yüksek saptanmışken ${ }^{32,33}$, AbdelFattah ve ark. ${ }^{34}$ erken başlangıçlı AGA'lı hastalarda HOMA-IR ile AGA arasında doğrudan bir ilişki saptamamış. Çalışmamızda, KiMK'nın kalınlığının artmasına neden olabilecek total kolestrol, LDL, trigliserid ve HOMA-IR değerlerinin yüksek olduğu saptandı. Bu bilgiler doğrultusunda metabolik sendrom ile AGA arasında ilişki olabileceği düşünülebilir.

\section{SONUÇ}

Erken başlangıçı AGA subklinik ateroskleroz ile ilişkili olabileceğinden KiMK ölçümü prematür kardiyovasküler hastalıkların teşhisi için önemli olabilir. Ayrıca metabolik sendrom ile erken başlangıçlı AGA arasında korelasyon olması nedeni ile günlük yaşamda yapılacak bazı değişiklikler olası morbiditelerin daha aza indirilmesi veya başlangıç zamanının ötelenmesinde gerekli önlemlerin alınmasını sağlayabilir.

\section{KISITLAMALAR}

Hasta sayısının yetersiz olması çalışmanın en önemli sınırlamasıdır.

\section{KAYNAKLAR}

1. Sperling LC. Hair and systemic disease. Dermatol Clin 2001;19:711-726.

https://doi.org/10.1016/S0733-8635(05)70310-7

2. Gathers RC, McMichael AJ. Hair disorders in systemic disease. Dermatologic Signs of Internal Disease. Ed. Callen J, Jorizzo J, Bolgnia JL, et al. 4. baskı. Elsevier, Saunders, 2003, 355-364.

3. Triantafyllidi H, Grafakos A, Ikonomidis I, et al. Severity of alopecia predicts coronary changes and arterial stiffness in untreated hypertensive men. J Clin Hypertens 2017;19(1):5157.
4. Banger HS, Malhotra SK, Singh S, Mahajan M. Is early onset androgenic alopecia a marker of metabolic syndrome and carotid artery atherosclerosis in young Indian male patients? International Journal of Trichinology 2015;7(4):141-147.

5. Serdaroğlu S, Oğuz O. Saç hastalıkları. Dermatoloji.Ed. Tüzün Y, Gürer MA, Serdaroğlu S, Oğuz O, Aksungur VL. 3. baskı. Istanbul, Nobel Tıp Kitabevi, 2008; 1295-1344.

6. Hamilton JB. Patternedloss of hair in man; typesandincidence. Ann N Y Acad Sci 1951;53(3):708-728. https://doi.org/10.1111/j.1749-6632.1951.tb31971.x

7. Lesko SM, Rosenberg L, Shapiro S. A case-control study of baldness in relation to myocardial infarction in men. JAMA 1993;269:998-1003.

https://doi.org/10.1001/jama.1993.03500080046030

8. Ford ES, Freedman DS, Byers T. Baldness and ischemic heart disease in a national sample of men. Am J Epidemiol 1996;143:651-657.

https://doi.org/10.1093/oxfordjournals.aje.a008797

9. Lotufo PA, Chae CU, Ajani UA et al. Male pattern baldness and coronary heart disease: the Physicians' Health Study. Arch Intern Med 2000;160:165-171.

https://doi.org/10.1001/archinte.160.2.165

10. Gathers RC, McMichael AJ. Hairdisorders in systemic disease. Dermatologic Signs of Internal Disease. Ed. Callen J, Jorizzo J, Bolgnia JL, et al. 4. baskı. Elsevier, Saunders, 2003, 355-364.

11. Kanters SD, Algra A, vanLeeuwen MS et al. Reproducibility of In Vivo CarotidIntima-Media Thickness Measurements Stroke 1997;28:665-671.

12. Mukherjee D. Carotid artery intima-media thickness: indicator of atherosclerotic burden and response to risk factor modification. Am Heart J 2002;144:753-9. https://doi.org/10.1067/mhj.2002.124865

13. Kuller L, Borhani N, Furberg C et al. Prevalence of subclinical atherosclerosis and cardiovascular disease and assosiation with risk factors in the Cardiovascular Health Study. Am J Epidemiol 1994;139(2):1164-79. https://doi.org/10.1093/oxfordjournals.aje.a116963

14. O'Leary DH, Polak JF. Intima-media thickness: a tool for atherosclerosis imaging and event prediction. Am J Cardiol 2002;90:18L-21L https://doi.org/10.1016/S0002-9149(02)02957-0

15. Sharma KH, Jindal A. Association between androgenetic alopecia and coronary artery disease in young male patients. Int J Trichology 2014;6:5-7. https://doi.org/10.4103/0974-7753.136747

16. Traish AM. Adverse health effects of testosterone deficiency (TD) in men. Steroids 2014;88:106-116. https://doi.org/10.1016/j.steroids.2014.05.010

17. Vigen $\mathrm{R}, \mathrm{O}^{\prime}$ Donnell $\mathrm{CI}$, Barón $\mathrm{AE}$ et al. Association of testosterone therapy with mortality, myocardial infarction, and stroke in men with low testosterone levels. JAMA 2013;310:18291836. https://doi.org/10.1001/jama.2013.280386

18. Rebora A. Baldness and coronary artery disease: the dermatologic point of view of a controversial issue. Arch Dermatol 2001;137:943-947.

19. Bolduc C, Shapiro J. Management of androgenetic alopecia. Am J Clin Dermatol 2000;1:151-158. https://doi.org/10.2165/00128071-200001030-00002

20. Triantafyllidi H, Trivilou P, Ikonomidis I et al. Is arterial hypertension control enough to improve aortic stiffness in untreated patients with hypertension? A 3-year follow-upstudy. Angiology 2015;66:759-765. https://doi.org/10.1177/0003319714552811 
21. Devereux R, Reichek N. Echocardiographic assessment of left ventricular mass in man. Circulation 1977;55:613-618. https://doi.org/10.1161/01.CIR.55.4.613

22. Dogramaci AC, Balci DD, Balci A et al. Is androgenetic alopecia a risk for atherosclerosis? J Eur Acad Dermatol Venereol 2009;23(6):673-7. https://doi.org/10.1111/j.1468-3083.2009.03137.x

23. Arias-Santiago S, Gutiérrez-Salmerón MT, CastelloteCaballero $L$ et al. Androgenetic alopecia and cardiovascular risk factors in men and women: a comparative study. $J \mathrm{Am}$ Acad Dermatol 2010;63(3):420-9. https://doi.org/10.1016/j.jaad.2009.10.018

24. Ertas R, Orscelik O, Kartal D, et al. Androgenetic alopecia as an indicator of metabolic syndrome and cardiovascular risk. Blood Press 2016;25(3):141-8. https://doi.org/10.3109/08037051.2015.1111021

25. Erdem S, Ünlü A. Asimetrik dimetil arginin ve klinik önemi. Selçuk Tıp Derg 2009;25(2):107-15.

26. Yoon JH, Kim JY, Park JK, Ko SB. Oxidative Damage Markers Are Significantly Associated with the Carotid Artery Intima-Media Thickness after Controlling for Conventional Risk Factors of Atherosclerosis in MenPLoSOne 2015;10(3):e0119731.

27. Kaya EH, Bulur I, Kocaturk E, Yildiz B, Saracoglu ZN, Alatas O. The role of oxidative stress in early-onset androgenetic alopecia. J Cosmet Dermatol 2016 Dec 16. https://doi.org/10.1111/jocd.12300

28. Banger HS, Malhotra SK, Singh S, et al. Is early onset androgenic alopecia a marker of metabolic syndrome and carotid artery atherosclerosis in young indian male patients? Int J Trichology 2015;7(4):141-7. https://doi.org/10.4103/0974-7753.171566

29. Agamia NF, Abou Youssif T, El-Hadidy A, El-Abd A. Benign prostatic hyperplasia, metabolic syndrome and androgenic alopecia: Is there a possible relationship? Arab J Urol 2016;14(2):157-62.

https://doi.org/10.1016/j.aju.2016.01.003

30. Gopinath H, Upadya GM. Metabolic syndrome in androgenic alopecia. Indian J Dermatol Venereol Leprol 2016;82(4):404-8. https://doi.org/10.4103/0378-6323.174421

31. Ekmekçi TR, Uçak S, Basat $O$, et al. The presence of insulin resistance and comparison of various insulin sensivity indices in women with androgenetic alopecia. Eur J Dermatol 2007;17(1):21-5.

32. González-González JG, Mancillas-Adame LG, FernándezReyes $\mathrm{M}$, et al. Androgenetic alopecia and insulin resistance in young men. Clin Endocrinol (Oxf) 2009;71(4):494-9. https://doi.org/10.1111/j.1365-2265.2008.03508.x

33. Mumcuoğlu C, Ekmekçi TR, Uçak S. The investigation of insulin resistance and metabolic syndrome in male patients with early-onset androgenetic alopecia. Eur J Dermatol 2011;21(1):79-82.

34. Abdel Fattah NS, Darwish YW. Androgenetic alopecia and insulin resistance: are they truly associated? Int J Dermatol 2011;50(4):417-22.

https://doi.org/10.1111/j.1365-4632.2010.04677.x 